\title{
The motives and barriers of association conference attendance: Evidence from an Australasian tourism and hospitality academic conference
}

\begin{abstract}
This paper reports on the motives and barriers to association conference attendance. Anecdotal evidence suggests that academics are facing increasingly constrained budgets for conference attendance. This paper seeks to confirm if this is indeed the case in reference to data drawn from an Australasian academic tourism and hospitality conference. The paper contributes to the growing body of literature on conference attendance motivations and supplements the lesser body of work on conference attendance barriers. The findings suggest that the delegates sampled were indeed receiving less support to attend conferences and this variously affected the prominence given to some motives and barriers for association conference attendance, with the motives more salient than the barriers in determining attendance. The paper concludes in proposing a research agenda aimed at ensuring the personal and professional benefits of attending academic association conferences continue into the foreseeable future.
\end{abstract}

Keywords: conference, academic association conferences, attendance motives, attendance barriers 


\section{Introduction}

Association conferences represent a large percentage of all conferences and conventions held worldwide. Association conferences refer to meetings of a practical or technical nature that are related to individual trade associations, professional societies or academic institutions (McCabe, Pool, Leiper, \& Weeks, 2000). Between 2006 and 2016, the number of association meetings held worldwide almost doubled, from just under 6000 in 2006 to over 12,000 in 2016 , representing the fifth decade of a continuous doubling of growth in the number of international association meetings (ICCA, 2017) ${ }^{1}$. Therefore, this is an important growth market for venues and destinations internationally.

One important component of the association conference sector is academic conferences. Most disciplines have annual or biennial conferences that are considered to be key dates on the academic calendar. However, the academic landscape is constantly changing and to keep up and provide products and services that are fit for purpose and attractive to the market, conference organisers must be aware of forces impacting on conference attendance.

Examining the tourism, hospitality and events (THE) fields, the disciplinary focus of the current study, there are two particular changes that are presently affecting the landscape for academic association conferences - the apparent proliferation of THE academic conferences; and the ways that academic conference travel is funded. Many universities are facing tougher budgetary constraints than they have in the past. In the Australian context, for example, universities are operating within an environment of constrained public budgets and are facing an unprecedented level of financial uncertainty (Universities Australia, 2017). One indicator of these financial pressures is the likely reduced access staff have to funds for discretionary travel, including for attending academic conferences. This may have a significant effect on the associations that host and stage academic conferences, particularly given that for many associations, their conference is their main income generating activity (Rogers \& Davidson, 2016).

Research on the drivers of delegate attendance and satisfaction is growing, and studies have identified some of the key attendance motivations as networking; personal/professional development and education; location; time and convenience; and health and well-being (Jago \& Deery, 2005; Mair \& Thompson, 2009; Rittichainuwat, Beck, \& Lalopa, 2001; Severt, Wang, Chen, \& Breiter, 2007). However, despite identifying the factors that lie behind attendance motivations, far less work has been focussed on understanding the barriers to attendance, or investigating how these barriers are affecting academic conference attendance motivations. Additionally, anecdotal evidence suggests that the changes in the academic landscape referred to above may be having an impact on academic conference attendance behaviour. This paper reports on research carried out in the Australasian context and examines the drivers and barriers of attendance to an academic THE conference with a view to examining how this academic landscape may be affecting conference attendance decisions. The paper will begin with a review of our current knowledge of conference attendance motivations and barriers.

\section{Literature Review}

\footnotetext{
${ }^{1}$ Note that to be included by ICCA, meetings must be organised by associations, must be held on a regular basis, have at least 50 delegates, and rotate between at least three countries (ICCA, 2017). Therefore, the number of association meetings held worldwide is much larger than the ICCA statistics would suggest.
} 
Traditionally, conferences have been divided into three main types (association, corporate and government), each of which have their own rationale, design and formats (Mair, 2015). Corporate conferences and meetings are usually held for business communications, i.e., board meetings, training meetings, sales meetings and conferences and new product launches (McCabe et al., 2000). Government conferences can be high profile international summits or training meetings for civil service departments, or anything in between (Mair, 2015). Associations, as organisations of persons with a common interest (Rogers \& Davidson, 2016), tend to hold large-scale conferences, and this is particularly the case for international associations. In addition, they are usually held annually (McCabe et al., 2000). For this reason, association conferences often last more than one day, and because of their size and scale are highly sought after amongst conference venues and destinations (Mair, 2015). This paper focuses on this type of conference, with particular reference to academic association conferences in the THE field.

\subsection{Conference attendance motivations}

There is a growing body of work on the motivations that encourage potential delegates to attend conferences, and to choose which conferences to attend when there are a number of potential options on offer. These can be categorised as either 'push' motivations (such the requirement to attend conferences to maintain a particular level of professional accreditation) and 'pull' motivations including an attractive location, and the opportunity to visit the surrounding area while travelling to the conference. Research suggests that these can be broadly considered under three main headings - networking; opportunities for personal and professional development and the conference location. There is ample discussion of these motivational factors elsewhere (see for example Jago \& Deery, 2005; Mair \& Thompson, 2009; Rittichainuwat et al., 2001; Severt et al., 2007), therefore this review will focus on the likely relevance of these factors to the academic association context. Other factors that may also play a role include the level of involvement of the potential delegates with the association hosting the conference (membership versus non-membership, but also whether the delegate plays a role in the association executive committee, or in special interest groups) and whether the delegate is required attend to represent their institution formally (Lee \& Back, 2007a).

Meeting people face-to-face at a conference is often regarded as useful and important, whether it be during the formal conference sessions, or less formally over drinks at the bar (Layng, 2009). Networks are acknowledged to be a key part of a successful career and therefore attendance at conferences may offer a chance to progress one's career outcomes (Mair \& Frew, 2017). Discussing topics of shared interest can lead to new ways of thinking about a problem or issue, may lead to future collaboration with other delegates, and can even be inspirational and motivating for delegates (Hixon, 2012). This is of particular importance in the academic sector since universities and competitive funding schemes increasingly reward academic staff for working with national and international collaborators on grant submissions, projects and joint publications. The opportunity for face-to-face networking, therefore, is a very valuable selling point for conference organisers and a powerful draw for potential delegates.

Rogers (2012) notes that learning and knowledge sharing are positive outcomes of conference attendance. Additionally, some conferences have more prestigious speakers and this will influence the decision of whether or not to attend. This is of particular relevance in the 
academic arena, with most disciplines using association conferences as vehicles for providing information on knowledge advances in the field, either through keynote and seminar presentations, or through more formal accreditation activities (for example, in relation to law, accounting or medicine). Additionally, for academics, presenting papers and disseminating the results of published studies and work-in-progress is an accepted and important part of both personal and professional development (Severt et al., 2007). Building an academic reputation is a vital part of a successful academic career, and presenting at conferences is a key component of this (Venkatesh, Morris, \& Ackerman, 2000).

Almost all studies into attendance motivation have uncovered a locational dimension (e.g., Lee \& Back 2007b; Mair \& Thompson, 2009; Yoo \& Zhao, 2010). As early as 1995, research by Witt, Sykes and Dartus suggested that a particularly attractive destination can be an influential factor in attendance: "when the destination is particularly 'interesting' or 'exotic', [...] conference attendance is likely to be stimulated" (p. 568). However, in a financially constrained environment, it may be the case that the accessibility of exotic or unusual locations comes under greater scrutiny, leading conference organisers to select locations such as capital or major cities that are chosen for their ease of access and cost-effective facilities. Nonetheless, this need not imply that the destination or venue should be considered pedestrian, and therefore less appealing. For example, in their research in the THE conference context, Mair and Frew (2017) highlighted the importance of 'backstage' or privileged access to venues such as zoos and historic buildings as part of the conference experience.

In addition to those motivational factors discussed above, other drivers of conference attendance such as fun and friendship can also be ascertained (Mair \& Frew, 2017). The social program of a conference has been recognised as a key part of conferencing (Opperman and Chon, 1995), but as Podilchak (1988) notes, fun is an important element for conference delegates too, which can contribute to making a conference a more memorable occasion. Additionally, as Foley, Edwards and Schlenker (2014) point out, having fun at a conference is likely to work in synergy with the opportunities for networking, allowing the formation of closer friend and working relationships. However, arguably academics may be loathe to draw attention to the non-work aspects of conferences in times of strained budgetary circumstances (although various social media postings seem to argue against this) (Mair \& Frew, 2017).

\subsection{Conference attendance barriers}

Naturally, there are a number of barriers that may prevent potential conference delegates from attending any given conference. These are usually accepted as including cost, time and health and safety (Mair \& Thompson, 2009; Severt et al., 2007). Other barriers may also exist, depending on the conference location, or prevailing conditions at the time of hostingsecurity threats, inclement weather and economic fluctuations can all have an impact on conference attendance (Rittichainuwat et al., 2001). As with the motivations for attendance, much of this is already represented in the literature in general terms, therefore, the following discussion will situate these barriers in respect of the academic conference attendance context.

In light of potentially constrained academic expenditure, cost is likely to represent the most potent barrier. Cost can refer to the cost of travel, accommodation, transport, conference registration or a combination of these (Yoo \& Zhao, 2010). Oppermann and Chon (1997) describe the idea of "freedom of choice" on the part of the association conference attendee, 
but whilst many academics do have some flexibility in terms of which conferences they would like to attend, many (if not all) are required to put together a case for why department or university funds should be used to support attendance. Therefore, while the individual's academic institution pays rather than the delegate, potential participants still need to work within their allocated budgets (Var, Cesario \& Mauser, 1985).

An additional factor that is likely to act as a barrier to conference attendance is having time available to travel to attend a conference (Oppermann \& Chon, 1997). Certainly the fact that many academic conferences are held at similar times of the year (usually during non-teaching periods) means there can be more than one conference that any academic can choose to attend. Indeed, schedule overlaps and conflicts were secondary reasons given for not attending a convention in an early study by Oppermann (1995). Although, it is likely that this remains an issue, perhaps a more pressing issue is the increasing academic teaching workload, which may be impinging on available time for research and conference attendance. Given that many academics are time poor, this is a major factor (Jago \& Deery, 2005). Academics, like other potential conference delegates, must weigh up the advantages of attending a conference versus other ways of spending their time, such as taking a family holiday, or spending time at home.

A final issue that plays a role in association conference attendance is whether the potential delegate feels that their health and wellbeing and their safety are assured at the conference location. In their study, Mair and Thompson (2009) identified a health and safety factor that was influential in terms of whether delegates elected to attend a conference. This included items such as being healthy enough to travel, feeling that medical facilities at the conference destination were available and safe, and having a positive image of the conference destination as being safe and secure (Mair \& Thompson, 2009). As was pointed out by Opperman and Chon (1997), travelling to attend a conference is not a leisure pursuit, and attending various sessions, preparing and delivering presentations and attending social functions combined with the rigours of long haul travel all contribute to making conference attendance a potentially tiring activity. Safety and security have been identified as playing an important role for meeting planners when selecting a venue (Crouch \& Louviere, 2004), and this was found to be of particular importance to female delegates in their attendance decision making (Ramirez, Laing \& Mair, 2012). Additionally, while little recent research has examined this issue in depth, the increase in the threat of international terrorism is almost certain to be influential in relation to conference travel (Mair, Jin, \& Yoo, 2016), and the importance placed on these issues is likely to continue to increase as time goes on, and new crises and disasters arise (Kang, Suh, \& Jo, 2005).

Given the barriers to attending, it is reasonable to question the extent to which face-to-face conferencing remains a viable option. Technology is certainly playing an increasingly important role in conferencing, allowing delegates to attend conferences virtually, and keep up to date with presentations from keynote speakers as well as permitting access to the parallel sessions. Social media has been described as a paradigm shift for traditional meetings and events (Palmer, 2010, cited in Lee, 2011). Online collaboration tools and social networking have also been proposed as potential ways to reduce the requirement for delegates to travel to attend conferences, thereby substantially reducing the need for conference funding (Pearlman \& Gates, 2010). Benefits of technology include offering content to important stakeholders who are not able to attend and allowing delegates to revisit content long after the final conference is over (Benjamin, 2017). 
Despite the prevalence of social media, and the increasing number of social media sites specific to business and academia, such as LinkedIn, Academia.com and ResearchGate, online conferencing does not provide the same experience as attending a conference and meeting colleagues and other delegates face-to-face. Indeed, face-to-face meetings have been demonstrated to be more effective than virtual meetings, in terms of positive outcomes (Pittman \& McLoughlin, 2012). Hixson (2012) identifies three key factors that make face-toface attendance particularly positive for delegates: attendance can instil motivation in delegates, along with the sense of being a member of a community of interest; the discussion of a shared topic of interest can lead to new ways of thinking about a problem or issue and can lead to new insights that may assist them to solve current problems at work; and encounters at conferences may even increase job satisfaction and lead to improved performance (Hixson, 2012). In other contexts, the importance of face-to-face contacts has also been highlighted. For example, in a more general sociological context, Urry (2002) notes that proximity and distance are important components of all social life and that people are linked in patterns of obligation, desire and commitment, increasingly over significant geographical distances. Urry (2002) therefore speaks to the notion of 'co-presence', highlighting the importance not only of opportunities to develop a sense of connection or belonging with various 'others' but also of the importance of ensuring that this is sensed and sustained, physically and virtually, despite the geographical distance. Such a need for copresence thus makes travel almost essential (Urry, 2002). Additionally, research by Wu, Waber, Aral, Brynjolfsson and Pentland (2008) suggests that face-to-face networking is associated with higher performance and productivity in the workplace, and that this is not just a result of physical co-presence, but rather of the meaningful conversations that flow between individuals when they are together. Again, these findings point to the importance of the faceto-face element of conferences, and highlight that this part of conferencing cannot easily be replaced by virtual or other substitutes.

Given the acknowledged benefits of attending conferences, and the extant literature that suggests there are strong motivating factors for association conference attendance, this paper reports on research that examines how these motivations for conference attendance are being affected in light of current university budgetary circumstances, and whether the barriers to attendance identified in the literature are playing more or less of a role in the context of academic association conferences than previously acknowledged.

\section{Methods}

In Australia and New Zealand, the Council of Australasian University Tourism and Hospitality Education (CAUTHE) Conference is the main annual forum for presenting research, hearing from keynote speakers, and networking with colleagues in the THE field. CAUTHE is the peak association in these countries representing the interests of professionals teaching and studying tourism, hospitality and events at bachelor degree level and above.

The CAUTHE conference takes place annually in February in either an Australian or New Zealand destination (recent conference locations include Dunedin, New Zealand in 2017; Sydney, Australia in 2016 and the Gold Coast, Australia in 2015). The conference takes place over three days and includes a full program of keynote sessions, panel sessions, concurrent paper presentation sessions and poster presentation sessions. The conference includes a oneday $\mathrm{PhD}$ scholar and Early Career Research (ECR) workshop and often has Special Interest Group (SIG) symposia that run shortly before or after the main conference. The CAUTHE 
conference is also well known for its lively social program (Lockstone-Binney, Mair, \& Whitelaw, 2016).

\subsection{Sample}

An online survey was administered using Qualtrics in late November 2013 to all CAUTHE members at that date and also to past attendees of the CAUTHE conferences. An initial email invitation and subsequent reminders were sent to 930 people with current email addresses on the association's database. 109 people responded to the survey, resulting in a response rate of $11.7 \%$.

\subsection{Data analysis}

The questionnaire used a 29-item scale developed by Mair and Thompson (2009) to assess the drivers and barriers of association conference attendance. This scale was used as it has been demonstrated to be reliable in Mair and Thompson's (2009) study of UK association conference attendance. Furthermore, there are few existing alternative association conference scales that could be adapted for the purposes of the study, or that would have provided significantly different items. All items were measured on a 5-point scale (1= Extremely unimportant through to $5=$ Extremely important), with Betz (1996) noting five to seven response categories are ideal. Additionally, the questionnaire included items to profile the scope and scale of academic conference attendance domestically and internationally and questions to determine whether conference attendance patterns have changed in recent years due to funding availability and other forces, thereby establishing baseline knowledge of the changes affecting conference funding for tourism and hospitality academics across a range of institutions in Australia, New Zealand and beyond.

Whilst it is relatively common for researchers to use parametric statistics such as t-tests and ANOVAs, for parametric testing to be appropriate, the data must be from a normallydistributed population (Field, 2013). Testing for skewness and kurtosis showed that the data collected here was not normally distributed. Data produced as a result of research in the field of social science is often not normally distributed and therefore different statistical tests are more appropriate (Pallant, 2013). Non-parametric testing was conducted using the chi-square test for relatedness and the Mann-Whitney $U$ test to test for differences between independent samples in relation to the motivation and barrier items and various categorical variables (Corder \& Foreman, 2014). The latter test ranks all response values from 1 to $n$, where $n$ represents the total number of values in the two groups. The ranks applicable to each group are then averaged and these findings are reported. The $\mathrm{p}$-value estimates the probability that a randomly chosen subject from one population will be more highly ranked than its equivalent from another population.

\section{Findings and Discussion}

The demographic profile of the returned sample revealed an equal 50/50 split of male and female respondents. Overwhelmingly, $83 \%$ of the respondents self selected the 'academic' option to reflect their occupational status, while $11 \%$ selected 'researcher/scholar' and $5 \%$ an 'other' category. Reflective of the geographic remit of the surveyed association, the majority of respondents $(56 \%)$ indicated their country of residence was Australia, 15\% were based in New Zealand, 11\% came from the United Kingdom and 6\% from Asia. The majority of respondents $(55 \%)$ were current association members at the time of the survey. 
In respect of academic conference attendance patterns, in a typical year, the majority of respondents attended on average one international and one domestic conference, with $45 \%$ having access to financial support from a Faculty or School dedicated fund, with a further $30 \%$ indicating support was based on their individual research performance. However, while the majority of respondents still received financial support for conference attendance, it is concerning to note that $61 \%$ had experienced decreased levels of institutional support for conference attendance over the preceding 2 -year period. Only $4 \%$ of respondents indicated more support was available to them. Interestingly, despite less funding support, the majority of respondents $(50 \%)$ were still attending the same number of conferences as before $(42 \%$ were attending a lesser number), which may suggest delegates are drawing upon other sources of funding (e.g., own funds) to maintain regular conference attendance. Upon further inspection, chi-square testing revealed a significant association between available conference support and conference attendance, $\chi^{2}(1, N=97)=11.00, p<.05$, with $77 \%$ of respondents attending less conferences over the last two years receiving less support over the same period.

In relation to those factors that appear to be influential in choosing to attend an academic conference, those most highly ranked by respondents speak to the core purposes of attending academic conferences. Respondents rated as important to them the opportunity the THE conference afforded to make professional contacts, learn about new research developments in their field and network with upcoming professionals. The prominence of these networking opportunities, and their associated chances for personal and professional development, align with the main drivers of conference attendance that have been found in the extant literature (Lee \& Back, 2007b; Mair \& Thompson, 2009; Severt et al., 2007). Additionally, the respondents highlighted social drivers of attendance as also being important, namely, the opportunity to meet old friends and spend time with like minded people. These findings support the more recent literature on the importance of conference attendance and friendship (Mair \& Frew, 2016). Table 1 illustrates the mean rankings for the motive items.

Table 1: Motives for Conference Attendance

\begin{tabular}{llll}
\hline Motives & N & Mean & Std. Dev \\
\hline Making professional contacts & 97 & 4.36 & 0.82 \\
Hearing new research in my field & 97 & 4.24 & 0.83 \\
Meeting old friends & 96 & 4.19 & 0.85 \\
Attendance financed by employer & 92 & 4.17 & 1.17 \\
Spending time with like-minded people & 97 & 4.11 & 0.79 \\
Meeting up-and coming professionals in my field & 97 & 4.00 & 0.85 \\
Establishing a reputation amongst my peers & 96 & 3.94 & 1.02 \\
Mixing with the global community & 97 & 3.94 & 0.93 \\
Interesting conference topic & 94 & 3.79 & 1.14 \\
Learning about a new subject & 97 & 3.78 & 0.91 \\
Professional advancement & 97 & 3.77 & 1.04 \\
Accessible location & 96 & 3.68 & 1.07 \\
Making new friends & 97 & 3.58 & 0.93 \\
Attractive location & 96 & 3.46 & 1.12
\end{tabular}




$\begin{array}{llll}\text { Being involved in the association } & 96 & 3.36 & 1.10 \\ \text { Safe destination } & 95 & 3.28 & 1.24 \\ \text { Getting out of the office } & 96 & 3.26 & 1.15 \\ \text { Fulfilling my job description } & 90 & 3.23 & 1.25 \\ \text { Visiting the surrounding area } & 97 & 3.15 & 1.22 \\ \text { Generating new business } & 91 & 2.68 & 1.13 \\ \text { Combining the conference with a visit to friends and } & 92 & 2.64 & 1.33\end{array}$

Table 2 illustrates the mean rankings of items assessing potential attendance barriers. Of Mair and Thompson's (2009) scale, the top three ranked items all related to conference costs in respect to the perceived cost of the conference (registration and transport) and the cost being covered by one's employer. Available medical facilities was the lowest rated item that could be considered a potential barrier, which is perhaps unsurprising given the roaming nature of the association conference between Australia and New Zealand and the provision of universal health care in both countries.

Table 2: Potential Barriers to Conference Attendance

\begin{tabular}{llll}
\hline Potential barriers & N & Mean & Std. Dev \\
\hline Cost of conference registration & 94 & 3.82 & 1.16 \\
Cost of transport & 95 & 3.80 & 1.15 \\
Cost of accommodation & 95 & 3.74 & 1.10 \\
Available time off / time away from work & 90 & 3.53 & 1.22 \\
No date clash with other conferences & 94 & 3.36 & 1.28 \\
No date clash with holidays already booked & 90 & 3.31 & 1.30 \\
Healthy enough to travel & 89 & 2.88 & 1.30 \\
Available medical facilities & 92 & 1.97 & 1.06
\end{tabular}

Comparing the mean results of the motives and barrier items in Tables 1 and 2, it is clear that the motive items were the more influential factors affecting the decision making of delegates to attend the association conference compared to the barrier items. Reiterating this point, the means of the top eight motive items (ranging from 4.36-3.94) were all well above the highest rated barrier item (3.82) in the delegates consideration set.

The non-parametric analysis revealed significant differences in the motivations and barriers of conference attendees based on gender, academic location, whether the respondent was a member of the association, level of conference attendance over the last two years, number of international conferences attended, available levels of conference support and type of available conference support.

In terms of gender, there were significant differences between male and female conference attendees based on two motive items. These included professional advancement $(\mathrm{U}=852.50$, $\mathrm{Z}=-2.445, \mathrm{p}<0.05$, median males $=4.00$, females $=4.00)$ and establishing a reputation amongst my peers $(\mathrm{U}=900.50, \mathrm{Z}=-2.097, \mathrm{p}<0.05$, median males $=4.00$, females $=4.00)$. The barrier available time off/ time away from work (Mann-Whitney $\mathrm{U}=772.50, \mathrm{Z}=-2.173$, 
$\mathrm{p}<0.05$, median males $=4.00$, females $=4.00)$ was also significant. In all cases, the mean ranks for these items were higher for females, indicating they placed greater importance on these factors. These findings are similar to studies that have suggested that there are significant differences between males and females in terms of their conference attendance motivations (e.g., Mair \& Frew 2017; Ramierez et al., 2012). Interestingly, despite previous research (e.g., Ramirez et al., 2013) suggesting that it would be the case, in the current study, female respondents did not rate their perceptions of their own safety as a barrier more highly than males. This underlines the need for further research investigating gender-based differences in conference attendance, a topic that remains under-researched, despite being highlighted as worthy of investigation as early as 2003 (Harris \& Ateljevic, 2003).

Noting the dominance of Australian and New Zealand attendees to the association conference, these respondents were combined for the purposes of analysing their data relative to attendees from the rest of the world. Only two significant differences arose with the mean ranks indicating respondents from the rest of the world rated healthy enough to travel $(\mathrm{U}=$ 583.00, $\mathrm{Z}=-2.027, \mathrm{p}<0.05$, median AUS/NZ = 3.00, rest of world $=3.00$ ) more highly, whilst Australian/New Zealand attendees, as the primary market for the particular association conference, rated establishing a reputation amongst my peers $(\mathrm{U}=661.50, \mathrm{Z}=-2.160, \mathrm{p}<$ 0.05 , median AUS/NZ $=4.00$, rest of world $=4.00$ ) more highly. As a barrier, health appears to be a more prominent consideration for those travelling from outside of Australia or New Zealand. Rather than this being a concern as to the standard of medical care on offer in the host countries, this may relate to the longer distance of travel required by rest-of-world delegates to attend the conference, difficulties associated with securing health insurance and/or paying for any medical care required when travelling internationally. Alternatively, this may also relate to Opperman and Chon's (1997) contention that conference travel can be a tiring pursuit and it is important for potential attendees to feel that they are well enough, not only to attend, but to get the most out of the conference. Interestingly, those receiving less financial support to attend conferences rated available medical facilities as more important compared to those receiving similar historic levels of conference support. Again, this may relate to the international nature of the conference, and the issues of paying for medical treatment in another country, but may also point to the dominant role played by the overall cost of travel.

As a proxy indicator of association involvement, analysis revealed only one significant difference between the conference attendance motives of current members and non-members of the association. As one would reasonably expect, the mean ranks indicated that being involved in the association $(\mathrm{U}=828.50, \mathrm{Z}=-2.517, \mathrm{p}<0.05$, median members $=4.00$, nonmembers $=3.00$ ) was more highly rated as a motive for attendance by current members. Additionally, as a barrier, cost of transport $(\mathrm{U}=805.50, \mathrm{Z}=-2.571, \mathrm{p}<0.05$, median members $=4.00$, non-members $=4.00$ ) was a more prominent factor for non-members, who on balance may more likely be first time conference attendees. An alternative explanation may be that the non-members of the association are also more likely to be international delegates, given that while the cost of the registration and the cost of accommodation are relatively similar for all delegates, the cost of transport differs substantially depending on where the attendee is travelling from.

Comparing conference attendance levels over the last two years revealed two significant differences between the cohort attending the same number of conferences as before as opposed to those attending less. The mean ranks indicated that for those experiencing less opportunities to attend conferences, cost of conference registration $(\mathrm{U}=719.00, \mathrm{Z}=-1.970$, 
$\mathrm{p}<0.05$, median same conferences $=4.00$, less conferences $=4.00)$ and cost of transport $(\mathrm{U}=$ $648.00, Z=-2.733, p<0.05$, median same conferences $=4.00$, less conferences $=4.00$ ) were more highly rated, suggestive of the premium placed on cost factors in the decision making processes of those facing constrained conference attendance. Additionally, this cohort placed greater value on their conference attendance meeting multiple needs with combining the conference with a visit to friends and relatives $(U=643.00, Z=-2.327, p<0.05$, median same conferences $=2.00$, less conferences $=3.00$ ) more highly rated in comparison to those attending the same number of conferences as before.

Specifically examining international conference attendance, comparison of those respondents attending one international conference per year versus those attending more than one highlighted two significant differences. Attendance financed by employer $(\mathrm{U}=360.00, \mathrm{Z}=-$ $2.582, \mathrm{p}<0.05$, median 1 conference $=5.00,2$ or more $=4.00$ ) was more highly valued by respondents attending only one conference per year, which may suggest those attending multiple conferences are less cost sensitive and more willing to fund their own attendance or may have greater access to funded speaking invitations. The mean ranks indicated that meeting old friends $(\mathrm{U}=448.00, \mathrm{Z}=-2.121, \mathrm{p}<0.05$, median 1 conference $=4.00,2$ or more $=5.00$ ) was also more highly rated by those attending more than one international conference per year, reinforcing the social links between conference attendance and international travel. This provides further evidence of the importance of fun and friendship in the decision making mix related to academic conference attendance, as proposed by Foley et al. (2014) and Mair and Frew (2017). However, it may also reflect a potentially inequitable situation if more senior academics, who are likely to be internationally recognised researchers in the field, are the cohort attending multiple conferences. Others, likely more junior academics, may not have access to the funding that would allow them to travel to multiple conferences, thus potentially disadvantaging them in relation to networking and future career opportunities. Additional research is required to confirm this supposition. No significant differences were found on the motive and barrier items for a likewise comparison of the extent of domestic conference attendance by the respondents.

Comparing respondents receiving the same amount of support to attend conferences over the last two years versus those receiving less financial support, the analyses revealed three significant differences. These differences related to the barrier of available medical facilities $(\mathrm{U}=703.00, \mathrm{Z}=-2.111, \mathrm{p}<0.05$, median same support $=1.00$, less support $=2.00)$ and the motives of visiting the surrounding area $(\mathrm{U}=779.50, \mathrm{Z}=-1.977, \mathrm{p}<0.05$, median same support $=3.00$, less support $=4.00)$ and learning about a new subject $(\mathrm{U}=717.00, \mathrm{Z}=-$ $2.620, \mathrm{p}<0.05$, median same support $=4.00$, less support $=4.00)$. In all cases, respondents receiving less financial support rated these items more highly. However, it should be noted that for the available medical facilities item, the median scores for both groups was relatively low $(1=$ Extremely unimportant, 2 = Unimportant $)$, indicating that regardless of them significantly differing in their assessments of this barrier, both groups rated it of low importance. The exact reasons for latter motive findings remain uncertain; however, it may be the case that delegates paying all (or a contribution towards) their travel costs use conferences as a base for a leisure holiday with partners and/or families. This is in line with the increasing trend towards what has become known as 'bleisure' - a blend of business and leisure travel characterised by adding on two or more days of leisure vacation to a business trip (Vivion, 2016). Additionally, using one's own money as a way to learn about a new subject may seem less of an imposition than having to pay to attend a conference for other reasons (for example, because one's institution or professional accreditation body requires it). 
Acknowledging that institutions in providing conference support to do so via differing mechanisms, further testing was conducted to assess if there were any differences between respondents receiving conference support based on research performance versus those who had to apply to a central fund for support. Only one significant difference on this basis was noted, with those receiving funding tied to performance placing a premium on learning about a new subject $(\mathrm{U}=509.00, \mathrm{Z}=-2.099, \mathrm{p}<0.05$, median performance $=4.00$, applying for funding $=4.00$ ). This may suggest that these academics, who have effectively earned their way to the conference, place priority on attending conferences that open their eyes to new subject or topic areas.

\section{Conclusions}

Academic association conferences are an under-researched area (Mair 2015), and this study provides significant contributions to our knowledge of this field. Collectively, the findings suggest tentative evidence of an increasingly constrained environment of reduced conference funding for academics to attend conferences, using data collected from delegates attending Australia and New Zealand's leading tourism and hospitality academic association conference. Whilst for the most part the findings suggest that respondents demonstrated similar motives and barriers for conference attendance, there were some notable differences based on variables examined.

In light of the constrained environment, non-association members and those attending fewer conferences placed a premium on the cost factors associated with the conference, including cost of transport and cost of registration. This mirrors findings from previous studies focused on non-academic conferences (e.g. Jago \& Deery, 2005; Severt et al., 2007). Cost of registration is almost completely under the control of the conference organiser to manipulate to ensure their conference remains attractive within a competitive choice set. However, the choice of destination and/or venue is also under the control of the organisers, at least to a certain extent (there may be factors which influence site selection, such as a need to rotate between particular destinations, or a requirement to select destinations where member organisations are based), and therefore the results of this study do provide further evidence for the contention that association conferences may increasingly have to select destinations such as capital cities, which are easily accessible, well served with a variety of transport options, and offer a range of accommodation providers to suit every budget. Such locational accessibility has been identified previously as being an important facilitator of conference attendance (Rittichainuwat et al., 2001).

Oppportunities the conference provided for delegates to network to advance their academic careers and establish reputations amongst peers were also important, particularly for females and Australian and New Zealand attendees. This resonates with the contention of Urry (2002) and $\mathrm{Wu}$ et al. (2008) who suggest that face-to-face contact, or co-presence, is a key part of networking and one which is likely to have long term implications in the workplace. The academic merit of conference itself in terms of it acting as a conduit for academics to learn about new research was important for both those receiving less conference support over the preceding two years and delegates for whom conference support was tied to research performance. In particular, for those who are required to meet certain performance criteria, the networking opportunities at academic conferences, and the potential for future collaborations arising from building such networks, appears to be highly significant. This is in accordance with the findings of Wu et al. (2008) and Hixon (2012) that meeting people in 
person, and the meaningful conversations that arise, can be motivating experiences for delegates. Therefore, while opportunities for networking have been idenfitied in previous studies as forming part of the conference attendance decision (e.g. Jago \& Deery, 2005; Mair \& Thompson, 2009; Rittichainuwat et al., 2001; Severt et al., 2007), this study has more clearly unpacked this dimension in the specific context of academic conferences.

The study also found that the various motivations studied were more important in the decision making mix than potential barriers when it came to deciding on whether or not to attend a conference. The inclusion of motives and barriers, which has enabled insight as to their relative saliency, extends the extant literature on attendance motivations by investigating in concert how both affect the determinants of academic association conference attendance.

Certain findings suggest that conference attendees are more closely aligning their attendance decisions to meeting multiple needs, including in the case of those attending less conferences, the opportunity to combine the conference with a visit to friends and/or relatives. At the other end of the spectrum, those attending more than one international conference per year, more favourably assessed the opportunities these fora facilitated for meeting old friends. In another example, delegates receiving less financial support were more attracted to visiting the surrounding area, highlighting the importance of conference venues situated in desirable locations and/or that can enable 'bleisure' opportunities. This has not emerged as being a significant component of decision-making in previous conference motivation studies, and therefore, this is a new finding and one of the main contributions of this study.

\subsection{Limitations and future research}

Naturally, there are limitations to this study that should be acknowledged. The disciplinary focus of the conference, THE, may mean that the findings cannot be generalised to academic association conferences influenced by differing disciplinary traditions (e.g., the physical sciences). The regional base of the association conference studied (Australia and $\mathrm{New}$ Zealand) may also affect generalisation of the results to associations or conferences in other countries or regions. Nonetheless, there is no particular reason to assume that there is anything different about academic conferences and associations in Australia and New Zealand, therefore the results are arguably likely to resonate with members of academic associations, and academic conference attendees in other parts of the world. Additionally, although the sample obtained was sufficient for the data analysis carried out, further investigation and testing on a larger scale, using randon sampling, would provide more generalisable results. Finally, the data were collected in 2013, and therefore data collected at a different time may yield some different results, although this is not anticipated.

In terms of future research, this study has highlighted interesting trends in relation to differences in how delegates rate the importance of various motivating factors and barriers depending on their gender, which are worthy of further study. Additionally, whilst not directly investigated in this research, the findings hint at issues relating to equity and accessibility at conferences, important given the crucial role of networking and professional development in academic promotions.

Given that majority of respondents noted reduced financial support for academic conference attendance, it is important to maintain a program of research investigating the barriers to attendance. As noted, many academic associations rely on memberships and conference 
registration income for their survival and any changes that threaten this income could have negative consequences for associations and the conferences that they stage. The benefits of attending conferences have long been demonstrated and therefore it would be a sad day if these benefits ceased be realised over time.

Finally, beyond the current study to confirm, research is required to evidence on what basis conference delegates are maintaining their levels of conference attendance in the face of reduced access to conference support. If indeed it is as we suspect, that academics and scholars are increasingly self-funding their attendance, in the future this will make association conference organisers more accountable to their direct customers (the delegate and not their host institution) for justifying costs associated with conferences, ensuring the topicality and quality of conference programs and selecting suitable conference locations and venues. 


\section{References}

Benjamin, K. (2017). How to manage hybrid meetings. CEI Asia. Retrieved from http://www.cei.asia/article/how-to-manage-hybrid-meetings/433780

Betz, N. E. (1996). Test construction. In F.T.L. Leong and J. T. Austin (Eds.), The psychology research handbook (pp. 239-50). Thousand Oaks, CA: Sage.

Corder, G. W., \& Foreman, D. I. (2014). Nonparametric statistics: A step-by-step approach ( $2^{\text {nd }}$ ed.). Hoboken, USA: Wiley.

Crouch, G., \& La Louviere, J. (2004). The determinants of convention site selection: A logistic choice model from experimental data. Journal of Travel Research, 43(2), 118-130. Field, A. (2013). Discovering statistics using IBM SPSS Statistics $\left(4^{\text {th }}\right.$ ed.). London, UK: Sage Publications.

Foley, C., Edwards, D., \& Schlenker, K. (2014). Business events and friendship: Leveraging the sociable legacies. Event Management, 18, 53-64.

Harris, C., \& Ateljevic, I. (2003). Perpetuating the male gaze as the norm: Challenges for 'her' participation in business travel. Tourism Recreation Research, 28(2), 21-30.

Hixson, E. (2012). The psychological benefits of attending conventions. In R. Mykletun (Ed.), Proceedings of the Global Events Congress 2012 (pp. 56-63). Stavanger, Norway: Universitetet i Stavanger.

ICCA. (2017). ICCA announces all-time record number of association meetings in 2016 [Press release]. Retrieved from http://www.iccaworld.org/npps/story.cfm?nppage $=6607$ Jago, L. K., \& Deery, M. (2005). Relationships and factors influencing convention decisionmaking. Journal of Convention and Event Tourism, 7(1), 23-42.

Kang, M.-H., Suh, S.-J. \& Jo, D. (2005) The competitiveness of international meeting destinations in Asia, Journal of Convention \& Event Tourism, 7(2), 57-85.

Layng, J. (2009). Make your contacts count: Networking know-how for business and career success. Business Communication Quarterly, 72(2), 252-255.

doi:10.1177/1080569908330438

Lee, M. J. \& Back, K.-J. (2007a) Effects of destination image on meeting participation intentions: Empirical findings from a professional association and its annual convention, The Service Industries Journal, 27(1), 59-73.

Lee, M. J. \& Back, K.-J. (2007b). Association members' meeting participation behaviors. Journal of Travel \& Tourism Marketing, 22(2), 15-33. 
Lee, S. (2011) 'To tweet or not to tweet: An exploratory study of meeting professionals' attitudes toward cpplying social media for meeting sessions. Journal of Convention \& Event Tourism, 12(4), 271-289.

Lockstone-Binney, L., Mair, J., \& Whitelaw, P. (2016). Academic conference attendance: Further insights from the CAUTHE conference survey. Proceedings of CAUTHE 2016 The Changing Landscape of Tourism and Hospitality: The Impact of Emerging Markets and Emerging Destinations (pp. 1210-1216). Sydney, Australia: Blue Mountains International Hotel Management School.

Mair, J. \& Frew, E. (2017). Academic conferences: A female duoethnography. Current Issues in Tourism. doi: 10.1080/13683500.2016.1248909

Mair, J. (2015). Conferences and conventions: A research perspective. Abingdon, UK: Routledge.

Mair, J., \& Thompson, K. (2009). The UK association conference attendance decisionmaking process. Tourism Management, 30(3), 400-409.

Mair, J., Jin, X. C., \& Yoo, J. J. E. (2016). Exploring the site selection decisions of incentive travel planners. Event Management, 20(3), 353-364.

McCabe, V., Poole, B., Weeks, P., \& Leiper, N. (2000). The Business and Management of Conventions. Brisbane, Australia: John Wiley \& Sons.

Oppermann, M. (1995). Professional conference attendees' and non-attendees' participation decision factors. Proceedings of The Society of Travel and Tourism Educators Annual Conference (pp. 25-37). Denver, USA: Society of Travel \& Tourism Educators.

Oppermann, M., \& Chon, K.-S. (1997). Convention participation decision-making process. Annals of Tourism Research, 24(1), 178-191.

Pallant, J. (2013). SPSS Survival Manual - A Step by Step Guide to Data Analysis Using IBM SPSS (5 $5^{\text {th }}$ ed.). Maidenhead, UK: Open University Press.

Pearlman, D. M., \& Gates, N. A. (2010). Hosting business meetings and special events in virtual worlds: a fad or the future? Journal of Convention \& Event Tourism, 11(4), 247-265. Pittman, J., \& Mclaughlin, B. (2012) Professional conferences, social capital and tourism: Is the alliance in jeopardy? Journal of Tourism \& Hospitality, 1(2), 1-3.

Podilchak, W. (1988). The neglect of fun in leisure: Denying social interaction. Leisure Information Quarterly, 14(3), 3-5.

Ramirez, D., Laing, J., \& Mair, J. (2013). Exploring intentions to attend a convention: A gender perspective. Event Management, 17(2), 165-178. 
Rittichainuwat Ngamson, B., Beck, J. A., \& Lalopa, J. (2001). Understanding motivators, inhibitors and facilitators of association members in attending international conferences. Journal of Convention and Exhibition Management, 3(3), 45-62.

Rogers, T. (2012). Conferences and conventions. Abingdon, UK: Routledge Rogers, T., \& Davidson, R. (2016). Marketing Destinations and Venues for Conferences, Conventions and Business Events ( ${ }^{\text {nd }}$ ed.). Abingdon, UK: Routledge.

Severt, D., Wang, Y., Chen, P., \& Breiter, D. (2007). Examining the motivation, perceived performance, and behavioral intentions of convention attendees: evidence from a regional conference. Tourism Management, 28(2), 399-408.

Universities Australia. (2017). 2017-18 Pre-Budget Submission Executive Summary.

Retrieved from https://www.universitiesaustralia.edu.au/Media-and-Events/submissions-andreports/2017-18-Pre-budget-submission

Var, T., Cesario, F. and Mauser, G. (1985). Convention tourism modelling. Tourism Management, 6(3), 194-204.

Venkatesh, V., Morris, M. G., \& Ackerman, P. L. (2000). A longitudinal field investigation of gender differences in individual technology adoption decision-making processes. Organizational Behavior and Human Decision Processes, 83(1), 33-60.

Vivion, N. (2016). Bleisure Travel: the benefist of mixing business travel with leisure.

Retrieved from: https://www.sabre.com/insights/bleisure-travel-the-benefits-of-mixingbusiness-travel-with-leisure/

Witt, S. F., Sykes, A. M., \& Dartus, M. (1995). Forecasting international conference attending. Tourism Management, 16(8), 559-570.

Yoo, J., \& Zhao, X. (2010). Revisiting determinants of convention participation decisionmaking, Journal of Travel \& Tourism Marketing, 27(2), 179-192. 